\title{
Observations of precipitation energies during different types of pulsating aurora
}

\author{
Fasil Tesema $^{1,2}$, Noora Partamies ${ }^{1,2}$, Hilde Nesse Tyssøy ${ }^{2}$, and Derek McKay ${ }^{3,4}$ \\ ${ }^{1}$ The University Centre in Svalbard (UNIS), Longyearbyen, Norway \\ ${ }^{2}$ Birkeland Centre for Space Science, University of Bergen, Bergen, Norway \\ ${ }^{3}$ Finnish Centre for Astronomy with ESO, FINCA, University of Turku, Turku, Finland \\ ${ }^{4}$ Sodankylä Geophysical Observatory, University of Oulu, Sodankylä, Finland
}

Correspondence: Fasil Tesema (fasil.tesema@unis.no)

Received: 30 June 2020 - Discussion started: 7 July 2020

Revised: 21 September 2020 - Accepted: 29 September 2020 - Published: 13 November 2020

\begin{abstract}
Pulsating aurora (PsA) is a diffuse type of aurora with different structures switching on and off with a period of a few seconds. It is often associated with energetic electron precipitation $(>10 \mathrm{keV})$ resulting in the interaction between magnetospheric electrons and electromagnetic waves in the magnetosphere. Recent studies categorize pulsating aurora into three different types - amorphous pulsating aurora (APA), patchy pulsating aurora (PPA), and patchy aurora (PA) - based on the spatial extent of pulsations and structural stability. Differences in precipitation energies of electrons associated with these types of pulsating aurora have been suggested. In this study, we further examine these three types of pulsating aurora using electron density measurements from the European Incoherent Scatter (EISCAT) VHF/UHF radar experiments and Kilpisjärvi Atmospheric Imaging Receiver Array (KAIRA) cosmic noise absorption (CNA) measurements. Based on ground-based all-sky camera images over the Fennoscandian region, we identified a total of 92 PsA events in the years between 2010 and 2020 with simultaneous EISCAT experiments. Among these events, 39, 35, and 18 were APA, PPA, and PA types with a collective duration of 58, 43, and $21 \mathrm{~h}$, respectively. We found that, below $100 \mathrm{~km}$, electron density enhancements during PPAs and PAs are significantly higher than during APA. However, there are no appreciable electron density differences between PPA and APA above $100 \mathrm{~km}$, while PA showed weaker ionization. The altitude of the maximum electron density also showed considerable differences among the three types, centered around 110,105 , and $105 \mathrm{~km}$ for APA, PPA, and PA, respectively. The KAIRA CNA values also showed higher values on av-
\end{abstract}

erage during PPA $(0.33 \mathrm{~dB})$ compared to PA $(0.23 \mathrm{~dB})$ and especially APA $(0.17 \mathrm{~dB})$. In general, this suggests that the precipitating electrons responsible for APA have a lower energy range compared to PPA and PA types. Among the three categories, the magnitude of the maximum electron density shows higher values at lower altitudes and in the late magnetic local time (MLT) sector (after 5 MLT) during PPA than during PA or APA. We also found significant ionization down to $70 \mathrm{~km}$ during PPA and PA, which corresponds to $\sim 200 \mathrm{keV}$ of precipitating electrons.

\section{Introduction}

The interaction between solar wind and the magnetosphere results in particle precipitation into the Earth's atmosphere through many different processes. Particles from the plasma sheet and radiation belts are accelerated and scattered into a loss cone to eventually collide with the species in the Earth's polar atmosphere. These collisions cause the atmospheric gas to glow in different shimmering bands of color in the sky, called aurora. The most common colors of the aurora are blue, green, and red at wavelengths of 427.8, 557.7, and $630.0 \mathrm{~nm}$, respectively. However, an auroral spectrum ranges from ultraviolet to infrared wavelengths depending on the type of atmospheric gas that undergoes emission. In general, the electrons generating aurora have energies ranging from $100 \mathrm{eV}$ to $100 \mathrm{keV}$, which affects the atmosphere by ionizing and changing the chemistry (Rees, 1969). The auroras are varied in appearance due to different magnetospheric pro- 
cesses; most are visible as discrete auroras with ribbons, arcs, and spirals, and some are visible as blinking patches of light called pulsating auroras (PsAs).

Pulsating auroras are mostly characterized as quasiperiodic low-intensity (a few kilo rayleigh) diffuse emission, which switches on and off with periods of a few seconds to a few tens of seconds (Royrvik and Davis, 1977; Yamamoto, 1988). The structures of PsA can be irregularly shaped patches or thin arcs elongated in an east-west direction (Wahlund et al., 1989; Böinger et al., 1996) and constantly evolving (Partamies et al., 2019). They usually occur at $100 \mathrm{~km}$ altitude and have a horizontal scale size ranging from 10 to $200 \mathrm{~km}$ (McEwen et al., 1981; Hosokawa and Ogawa, 2015; Nishimura et al., 2020). The average duration of PsA is around $2 \mathrm{~h}$ (Jones et al., 2011; Partamies et al., 2017; Bland et al., 2019; Tesema et al., 2020); however, some very long durations $(15 \mathrm{~h}$ ) have also been reported (Jones et al., 2013). Pulsating auroras are frequently observed in the nightside equatorward boundary of the auroral oval and during substorm recovery phases in the morning sector. Depending on the level of geomagnetic activity, the time and location of PsA may vary. This variation ranges from observing at all local times during intense geomagnetic activity to being localized to midnight to the morning sector around $68^{\circ}$ magnetic latitude during weak geomagnetic activity.

Most of the investigations related to pulsating aurora have been multi-measurement case studies using, for instance, allsky cameras (ASCs), radars, rockets, riometers, and satellite measurements (Jones et al., 2009; Lessard et al., 2012; McKay et al., 2018; Yang et al., 2019; Nishimura et al., 2020). However, recently a considerable number of statistical findings have been documented, specifically using optical, satellite, incoherent scatter radars, and Super Dual Auroral Radar Network (SuperDARN) measurements (Jones et al., 2011; Hosokawa and Ogawa, 2015; Partamies et al., 2017; Grono and Donovan, 2018; Bland et al., 2019; Grono and Donovan, 2020; Tesema et al., 2020). It is now well documented that the energies associated with PsA span a wide range from tens to hundreds of kiloelectron volts (Miyoshi et al., 2010, 2015). Pulsating aurora electrons are generally accepted to originate from the magnetosphere near the equatorial plane through pitch angle scattering of energetic electrons into the loss cone by plasma waves (Nishimura et al., 2010, 2011). A source in the magnetospheric equatorial plane implies that pulsating aurora is observed in both hemispheres. However, different shapes and pulsating periods of PsA between hemispheres have also been reported (Watanabe et al., 2007; Sato et al., 2004).

A significant number of studies have used incoherent scatter radars to study the ionization, structure, and energies of precipitating electrons associated with PsA (Wahlund et al., 1989; Böinger et al., 1996; Jones et al., 2009; Hosokawa and Ogawa, 2015; Miyoshi et al., 2015). A recent study by Hosokawa and Ogawa (2015) showed a higher European Incoherent Scatter (EISCAT) electron density at lower altitudes during PsA, which is more pronounced in the morning sector. Similarly, Oyama et al. (2016) showed a maximum electron density below $100 \mathrm{~km}$ during a pulsating aurora. Jones et al. (2009) utilized ionization from incoherent scatter radar in Poker Flat, Alaska, to estimate the energy distribution of PsA electrons and compared it with rocket measurements. They showed that the layer of maximum electron density associated with pulsating patches has a thickness (full width at half maximum) of $\sim 15-25 \mathrm{~km}$. Miyoshi et al. (2015) used EISCAT electron density, Van Allen Probes, and optical data to study the source and the energy of precipitating electrons during PsA. They identified electron density enhancement at altitudes above $68 \mathrm{~km}$ associated with the pulsating aurora. Hosokawa and Ogawa (2010) showed a significant ionization in the E region and upper part of the D region $(80-95 \mathrm{~km})$ due to energetic precipitation during PsA. This ionization in the $\mathrm{D}$ region leads to the appearance of the Pedersen current layer exactly at the altitudes where pulsating ionization occurs and plays a vital role in modifying the current system in the ionosphere. Hosokawa et al. (2010) used hightime-resolution electron density data during PsA and identified enhanced electron density in the E region $(95-115 \mathrm{~km})$. They further indicated that the intense ionization could lead to a significant effect on the ionospheric conductivity and current system and, in turn, affect the motion and shapes of PsA patches. Hard precipitation of PsA electrons is known to reach below $70 \mathrm{~km}$ and can ionize and change the chemistry of the mesosphere (Turunen et al., 2009, 2016; Tesema et al., 2020). It has also been shown by model results that not all PsA electrons cause strong ionization and chemical changes (Tesema et al., 2020).

Ionospheric absorption of cosmic radio noise at the $\mathrm{D}$ region altitudes has been observed during energetic particle precipitation $(>10 \mathrm{keV})$ associated with PsA (Milan et al., 2008; Grandin et al., 2017; McKay et al., 2018; Bland et al., 2019). Riometric absorption in the ionosphere covers a range of altitudes in the $\mathrm{D}$ and $\mathrm{E}$ regions that contribute to the observed absorption (Wild et al., 2010; Rodger et al., 2012). Thus, observing a one-to-one correspondence between PsA and ionospheric absorption (Grandin et al., 2017; McKay et al., 2018) further suggests that PsA electrons' energy also covers large ranges. However, the cosmic noise absorption (CNA) values are reported to be low during PsA (below $\sim 0.5 \mathrm{~dB}$ ), compared to substorm values (above $\sim 1 \mathrm{~dB}$ ). These low values suggest that the flux of energetic electrons during substorms is significantly larger than during PsA. High-frequency radio attenuations in the D region from the SuperDARN radars can also be used to detect energetic electron precipitation associated with PsA (Bland et al., 2019).

Based on pulsation, lifetime, and spatial extent, a recent study by Grono and Donovan (2018) categorized pulsating aurora into three groups: patchy, amorphous, and patchy pulsating aurora. Patchy aurora (PA) consists of stable emission structures with pulsations over a limited area of the 
spatial extent. A patchy pulsating aurora (PPA) is made up of steady emission structures with pulsations over a large fraction of their spatial extent, and the amorphous pulsating aurora (APA) is unstable and rapidly varying pulsating aurora. PPA and PA follow the magnetospheric convection, while APA is more dynamic and does not follow the magnetospheric convection. The occurrence probability of the different types of PsA is reported by Grono and Donovan (2020). The most dominant type is APA, followed by PA and PPA. They concluded that before midnight the typical PsA type is APA, while PPA and PA are more common in the late morning. They also estimated the average location of the source regions using T89 model mapping. Before midnight, the source of all types of PsA is constrained in the same area, while after midnight APA extends further out in the magnetosphere.

An investigation of a few PsA events by Yang et al. (2019) showed a high correlation between CNA absorption and emission intensity of the APA type, but no correlation with PPA emission intensity. They also reported the possibility of an extended higher energy range during APA compared to PPA using satellite measurements of a single event. Recently, Tesema et al. (2020) suggested that the abrupt changes in the statistical energy spectrum curve of PsA might be associated with mixing different types of PsA. PsA structure change between patch-like and arc-like, and having a characteristic of changing patch size through time in general, is suggested to be related to the change in precipitation energy (Partamies et al., 2017, 2019). The question of what are the sources and mechanisms driving different PsAs is still unanswered. A key step to answering this question is to quantify the associated electron fluxes and spectra. In this study, we therefore investigate the altitude and level of ionization, which are related to energies and flux of precipitating electrons, during different PsAs. We use electron density measurements from EISCAT VHF/UHF radars and CNA measurements from the Kilpisjärvi Atmospheric Imaging Receiver Array (KAIRA) riometer. The EISCAT radars and KAIRA measure the impact from electrons that is truly lost in the atmosphere, compared to incomplete loss cone observations from, for instance, satellite observations. Thus, the height and magnitude of maximum electron density are an indirect measure of energies and flux of precipitating electrons, respectively.

\section{Materials and methods}

The optical data used in this study are from groundbased ASCs operated by the Finnish Meteorological Institute (FMI). The FMI Magnetometers-Ionospheric Radars-Allsky Cameras Large Experiment (MIRACLE) network consists of nine ASCs located in the Fennoscandian region. The database has been a huge data source in auroral studies for more than 40 years. As technological advancements were growing and the ASC quality was degrading in time, two of

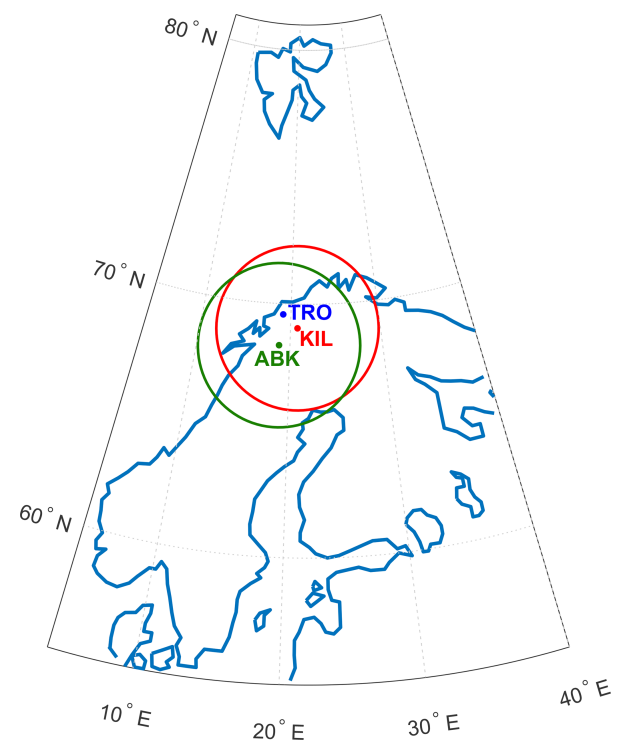

Figure 1. Geographic locations of ground-based ASC stations (KIL and $\mathrm{ABK}$ ) from the MIRACLE network and locations of EISCAT radars (TRO). KAIRA FOV is the same as KIL ASC.

the digital ASCs with intensified charge-coupled devices (ICCDs) were replaced with the newer technology of electronmultiplying CCDs (EMCCDs) in 2007. Such cameras are more suitable for studying very faint auroral structures (Sangalli et al., 2011), like pulsating aurora, in detail. For event identification, the entire data set in this study is from these newer cameras. We use images filtered for the green emission at $557.7 \mathrm{~nm}$ in addition to a few events with images of the blue emission at $427.8 \mathrm{~nm}$. From the nine ASCs, we used Kilpisjärvi (KIL, $69.02^{\circ} \mathrm{N}, 20.87^{\circ} \mathrm{E}$, geographic) as our primary data source. However, when there were no data at $\mathrm{KIL}$, a nearby site, Abisko (ABK, $68.36^{\circ} \mathrm{N}, 18.82^{\circ} \mathrm{E}$, geographic), was used as a substitute. The fields of view (FOVs) of both sites cover a large area around the FOV of EISCAT radars located in Troms $\varnothing$, as shown in Fig. 1.

To study the ionization associated with PsA, we examined electron density measurements from the EISCAT radar located at Troms $\varnothing$, Norway $\left(69.58^{\circ} \mathrm{N}, 19.21^{\circ} \mathrm{E}\right.$, geographic). The EISCAT radar system consists of UHF and VHF radars, which operate at frequencies of 931 and $224 \mathrm{MHz}$, respectively (Rishbeth and Williams, 1985). We used Common Programme One (CP1), Common Programme Two (CP2) radar modes for UHF, and Common Programme Six (CP6) radar mode VHF radars. These modes are suitable for observing ionization in the $\mathrm{D}$ and $\mathrm{E}$ regions with a range resolution of $<6 \mathrm{~km}$ during particle precipitation events. Details about the radar modes can be found at https://eiscat. se/scientist/document/experiments/ (last access: 4 November 2020). During the pulsating auroras, either the UHF or VHF radar was operative, and electron density was obtained in either the field-aligned or zenith measurements. We then 
used the magnitude and altitude of electron densities during different types of PsA to understand the flux and energy of electrons associated with them.

We identified 92 pulsating aurora events observed simultaneously by ASC at KIL or ABK and the EISCAT radars at Troms $\varnothing$ (see Fig. 1). The temporal resolutions of optical data was $\leq 10 \mathrm{~s}$, and that of the radar data was $1 \mathrm{~min}$. This period is significantly longer than the typical period of PsA, which does not allow separation of the on and off phases of PsA. Thus, all the results presented in this study are average statistics over on and off periods of PsA. Types of PsA are identified using keograms and ewograms generated at the location of the ASC, as described by Grono and Donovan (2018). As these quick-look data formats are not always sufficient and accurate for detecting types of PsA, especially during the transition between types, we used individual all-sky camera images to confirm the detection. APA can be distinguished from the other PsA types by looking at the ewograms and identifying periods where there are no apparent speed line tracings (i.e., similar structures shown by a blue arrow on the second panel of Fig. 2). PPA and PA have more persistent structures, which enables us to identify them quickly. Since PPA has a pulsating nature over a wider spatial extent of otherwise stable patches, striations (alternating bright and dim states of PsA) in the speed line on ewograms are used to differentiate them from PA. During PA, the speed lines have no vertical striations. Once all PsA with at least a few minutes ( $>10 \mathrm{~min}$ ) duration were divided into the three subcategories, we then investigated the altitude profile of PsA ionization. The altitude of the maximum electron density and the magnitude of the electron density provide indirect information about the energy and flux of the precipitating PsA electrons, respectively.

Because PsAs cover a wide range of altitudes and electron energies, comparing the altitude and magnitude of maximum electron density does not always provide the full information on the precipitating electrons. For a detailed investigation of electron density between different PsA types, we average the electron density into five groups with altitude steps of $10 \mathrm{~km}$ between 70 and $120 \mathrm{~km}$. Two of them, between 110 and $120 \mathrm{~km}$ and between 100 and $110 \mathrm{~km}$, are groups in the E region, and the other three - between 90 and $100 \mathrm{~km}$, between 80 and $90 \mathrm{~km}$, and between 70 and $80 \mathrm{~km}$ - are groups in the $\mathrm{D}$ region of the ionosphere.

We also used measurements of CNA made using KAIRA: a radio-receiving system located at Kilpisjärvi in northern Finland (McKay et al., 2015). An observing frequency of $38.086 \pm 0.098 \mathrm{MHz}$ was used. Signals from the 48 low-band antennas of KAIRA were cross-correlated with a sample integration of $1 \mathrm{~s}$ to form antenna covariance matrices. All-sky radio images can be formed from these using 2D Fourier transforms, which have a zenith spatial resolution of approximately $24 \mathrm{~km}$ at $90 \mathrm{~km}$ altitude. However, to achieve the same effect as an optical keogram, only a 1D Fourier transform of the meridian pixels is made for each time sample, thus form- ing a "riometric keogram" - or riogram. CNA is determined as $A=10 \log _{10}\left(P_{\mathrm{q}} / P\right)$, where $A$ is absorption in decibels, $P$ is the observed power, and $P_{\mathrm{q}}$ is the quiet-sky power derived from a median of meridian slices from equivalent sidereal times over a period of $14 \mathrm{~d}$ prior to the observation.

The separation between the locations of the FMI camera and KAIRA array is $\sim 2.27 \mathrm{~km}$. This proximity means that for observations of ionospheric phenomena in the $\mathrm{D}$ region they have nearly coincident sky coverage. Since the field of view of EISCAT lies within the all-sky absorption image, comparing results obtained from EISCAT and KAIRA is also possible. The KAIRA facility has previously been used to study pulsating aurora (Grandin et al., 2017; McKay et al., 2018). The riometry data corpus from KAIRA spans from 2014 to 2020 and includes 50 events out of the 92 events identified using optical data.

\section{Results}

By inspecting 11 years (between 2010 and 2020) of ASC images from the FMI-MIRACLE network in combination with EISCAT electron density measurements, we identified PsA events based on classification implemented in Grono and Donovan (2018) and Yang et al. (2019). In the process, we produced high-time-resolution keograms and ewograms ( $\sim 10 \mathrm{~s}$ cadence instead of $1 \mathrm{~min}$, as in quick-look data) from ASC images at KIL and ABK. Examples of events that consist of all the three types of PsAs within a single event are shown in Figs. 2, 3, and 4. The panels in these figures from top to bottom show the keogram, ewogram, EISCAT electron density, and altitude of maximum electron density, and an additional panel with KAIRA CNA riogram in Fig. 4. The dashed red line overlaid in the keograms (ewograms) is the latitude (longitude) of the EISCAT radar. In Fig. 2, the APA type is observed between 00:30 and 01:06 UT (green shading), PPA between 01:06 and 01:26 UT (red shading), and PA between 01:26 and 02:00 UT (purple shading). During these intervals, a single type was dominant over the FOV of the ASC and/or EISCAT. However, after 02:00 UT, the APA type starts to be apparent in the northwestward direction and lasts until 03:10 UT. After that, the APA type fills the FOV of the camera. For this event, the PsA type between 02:00 and 03:10 UT is labeled as PA, because the EISCAT radar beam lies within this type of PsA as indicated by dashed red lines. The third panel in Fig. 2 shows the electron density profiles. During APA, the electron density $\left(N_{\mathrm{e}}\right)$ enhancement shows significant values above $100 \mathrm{~km}$, which is apparent at the beginning and end of this event. In between, we observe PPA and PA types, for which the $N_{\mathrm{e}}$ shows higher values, mostly below $100 \mathrm{~km}$. A corresponding substantial $N_{\mathrm{e}}$ enhancement is observed when the patchy aurora lies in the FOV of the radar after 01:30 UT. The $N_{\mathrm{e}}$ enhancements during these PsA types reach down to $70 \mathrm{~km}$. The last panel in Fig. 2 shows the altitude of the maximum $N_{\mathrm{e}}$, illustrating a gradual decrease 


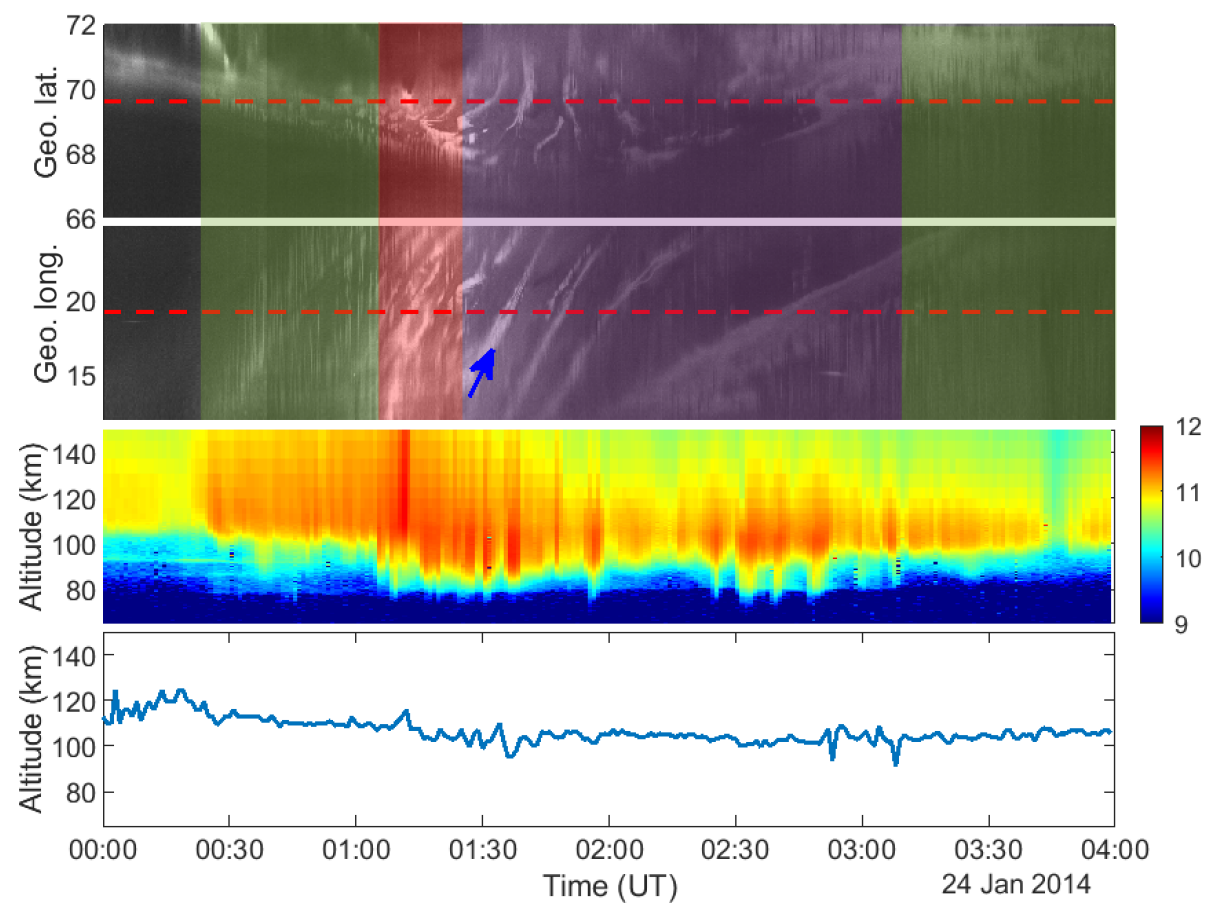

Figure 2. Keogram, ewogram, EISCAT electron density, and altitude of maximum electron density on 24 January 2014. The dashed red lines are the latitude and longitude of the EISCAT radar's FOV. PsA types - APA (green), PPA (red), and PA (purple) - are marked with rectangles in the keograms and ewograms.

in height at the beginning and a slight increase at the end of the event. However, equivalent substantial differences in $N_{\mathrm{e}}$ observed below $105 \mathrm{~km}$ between APA and the other two are not captured by the height of maximum electron density.

Figure 3 shows the three types of PsA in a single event on 25 January 2012, which lasts more than $6 \mathrm{~h}$. The panels displayed in the figure are the same as in Fig. 2. Inspection of this figure shows that different types of PsA are observed in different regions of the sky. Before 02:00 UT APA is dominant below $70^{\circ}$ latitude followed by a combination of faint unstructured and very low emission up until 03:00 UT. After that, PPA becomes dominant below $68^{\circ}$ latitude; however, over the EISCAT FOV APA is dominant until 04:00 UT. After 04:00 UT, almost the entire sky is filled with PPA, and then, after 05:30 UT, PA starts to appear. The $N_{\mathrm{e}}$ and its maximum altitude in the EISCAT FOV (dashed red lines in keograms and ewograms) are displayed on the lower two panels of the figure. There is a clear difference in the magnitude of electron density and the altitude of maximum $N_{\mathrm{e}}$ during the different types of PsA. The interesting big difference is observed around 04:00 UT, where there was a transition between APA and PPA. This transition is also apparent at the altitude of the maximum $N_{\mathrm{e}}$. During APA, the maximum $N_{\mathrm{e}}$ altitude lies at $110 \mathrm{~km}$; however, during PPA, it is below $100 \mathrm{~km}$. The PA electron density magnitudes and the altitude of the maximum $N_{\mathrm{e}}$ show high variations corresponding to the patch-on and patch-off periods over the EISCAT FOV.
Figure 4 shows similar panels to those displayed in Figs. 2 and 3 with an additional panel of KAIRA CNA riogram with the EISCAT FOV marked by the dashed red line. In this figure, before 01:00 UT, the APA type of PsA on the top panel is far away from the EISCAT FOV. However, just before 01:00 UT, a different non-pulsating type of auroral activity becomes visible over EISCAT. This is followed by PPA for a very short duration; then up until 02:00 UT, APA is dominant. Between 02:00 and 03:00 UT, PPA followed by PA was observed. The $N_{\mathrm{e}}$ also shows considerable differences during the different PsA types. A significant $N_{\mathrm{e}}$ magnitude enhancement below $80 \mathrm{~km}$ around 02:15 UT is seen during PPA. But such a transition is not apparent at the altitude of the maximum electron density. Furthermore, the close correspondence between the CNA values and the emission in the keogram is evident. The CNA values, along with the EISCAT FOV and how deep the ionization occurred, have a nearly one-to-one correspondence. The CNA values during PPA are above $1 \mathrm{~dB}$, while during APA CNA is below $1 \mathrm{~dB}$.

The thickness (full width at half maximum) of PsA ionization during these three types of PsA showed large differences. Individual electron density profiles illustrated that PA ionization has a layer thickness of about $20 \mathrm{~km}$, followed by APA with $30 \mathrm{~km}$ and PPA with $40 \mathrm{~km}$ thickness. This is consistently the same in all the three examples displayed in Figs. 2, 3, and 4, and from all the electron density profiles in the study (not shown here). A deeper and higher ioniza- 


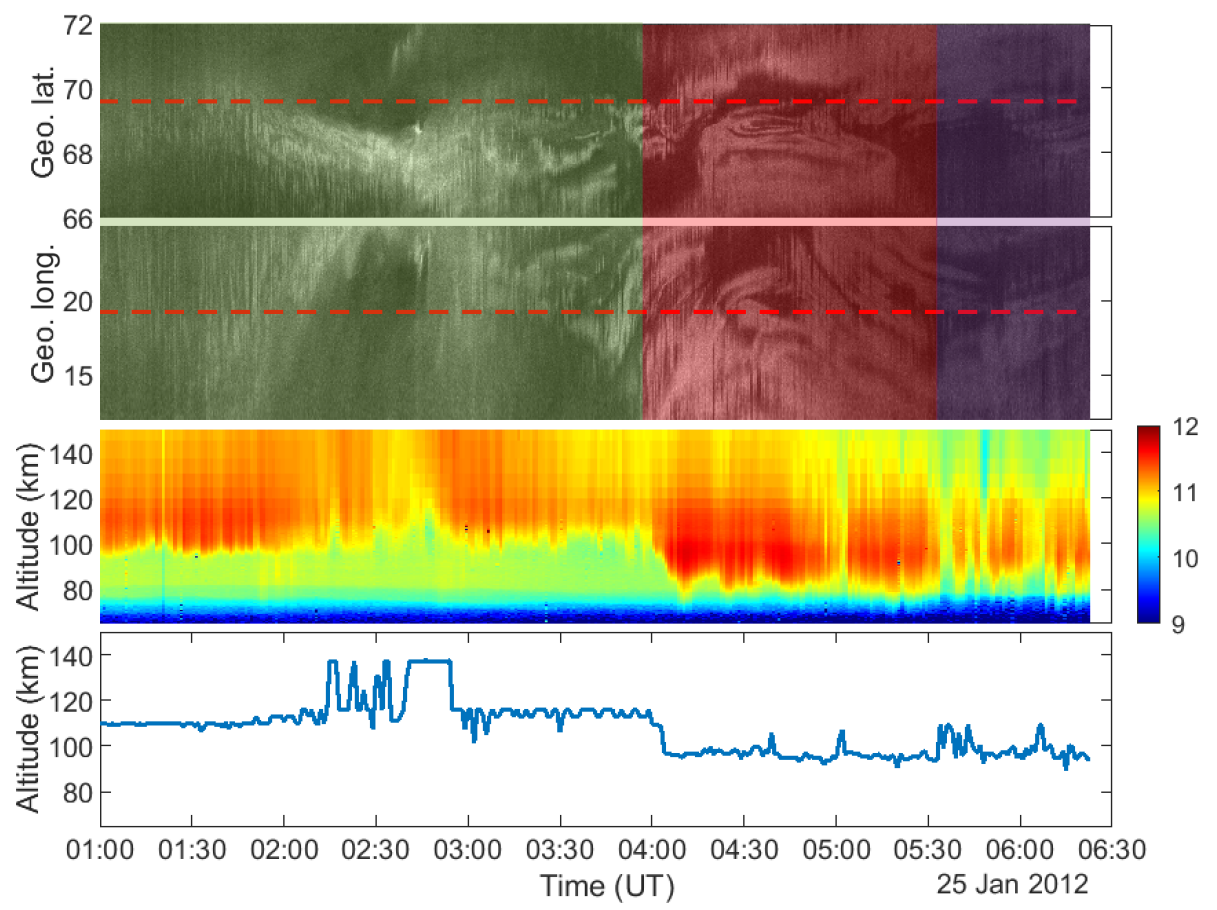

Figure 3. Keogram, ewogram, EISCAT electron density, and altitude of maximum electron density on 25 January 2012. Color-coded rectangles and dashed red lines are PsA types and EISCAT FOV respectively, the same as in Fig. 2.

tion was observed when the patchy aurora was passing over the FOV of EISCAT. This is also apparent in the height of the maximum electron density plots with high variations in altitude during the patch-on and patch-off periods.

As the altitude of the maximum $N_{\mathrm{e}}$ is a single point, it does not reflect the differences in $N_{\mathrm{e}}$ we observe along with the height profile. For example, in Fig. 4, the maximum electron density altitude barely changes, while electron densities during different PsA types at different altitudes show significant transitions. To include this information in the comparison, we average electron densities in height bins during different types of PsA. Figure 5 shows a histogram of these averages in $10 \mathrm{~km}$ intervals between 70 and $120 \mathrm{~km}$ (panels a-e), as well as a histogram of the maximum altitude electron density (f) for the entire data set (APA $\sim 58 \mathrm{~h}, \mathrm{PPA} \sim 43 \mathrm{~h}, \mathrm{PA} \sim 21 \mathrm{~h}$ ). As shown in Fig. 5a and b, there is not much difference in $N_{\mathrm{e}}$ between APA and PPA types at heights above $100 \mathrm{~km}$. However, PA ionization shows a significant reduction in the 110 $120 \mathrm{~km}$ region but similar distributions to those of APA and PPA in the $100-110 \mathrm{~km}$ region. In panels (c), (d), and (e) which correspond to average $N_{\mathrm{e}}$ between 90 and 100, 80 and 90 , and 70 and $80 \mathrm{~km}$, respectively - a substantial shift to the higher $N_{\mathrm{e}}$ is observed during PPA compared to APA and PA. In the three groups of the D region (70-80, 80-90, and 90$100 \mathrm{~km}$ altitude ranges), PPA $\log 10\left(N_{\mathrm{e}}\right)$ values are centered around $9.9,10.7$, and $11.3 \mathrm{~m}^{-3}$, respectively. However, during APA these values are 9.3,10.1, and $10.8 \mathrm{~m}^{-3}$. According to Fig. 5f, precipitation during PPA and PA penetrates deeper on average as compared to APA. The maximum $N_{\mathrm{e}}$ during PPA and PA primarily lies below $105 \mathrm{~km}$, while during APA it is above $105 \mathrm{~km}$.

To further understand the differences between types of PsA, we statistically analyzed the peak electron density and altitude, as shown in Fig. 6. Figure 6 is a two-dimensional histogram, in which the number of points are color-coded, and shows the time evolution of the altitude and magnitude of the maximum electron density. Most of the events were observed between midnight and 9 MLT (magnetic local time; 07:30 UT), where PPA is more dominant after 5 MLT and there is no PA before magnetic midnight. The PsA altitude tends to be lower in the morning sector, especially for PPA and PA. The altitude decrease in the morning sector is significant in the PPA type, reaching down to $95 \mathrm{~km}$, while the magnitude of the maximum $\log 10\left(N_{\mathrm{e}}\right)$ stays above $11.3 \mathrm{~m}^{-3}$. The magnitude of the maximum $N_{\mathrm{e}}$ is higher and more persistent during PPA. However, during PA and APA, the maximum $N_{\mathrm{e}}$ varies a lot with smaller amplitudes (below $11.5 \mathrm{~m}^{-3}$ ). Generally, it is seen that the height of the peak electron density reaches below $100 \mathrm{~km}$ during PPA and PA, while during APA it stays predominantly above $100 \mathrm{~km}$.

The cosmic noise absorption from KAIRA during the three types of PsA is shown in Fig. 7. During PPA, the CNA is relatively high compared to the other two types. Based on this figure, the absorption during PPA after 2 MLT shows high values, while the absorption due to APA starts to decline. CNA values during APA are predominantly below $0.5 \mathrm{~dB}$; 


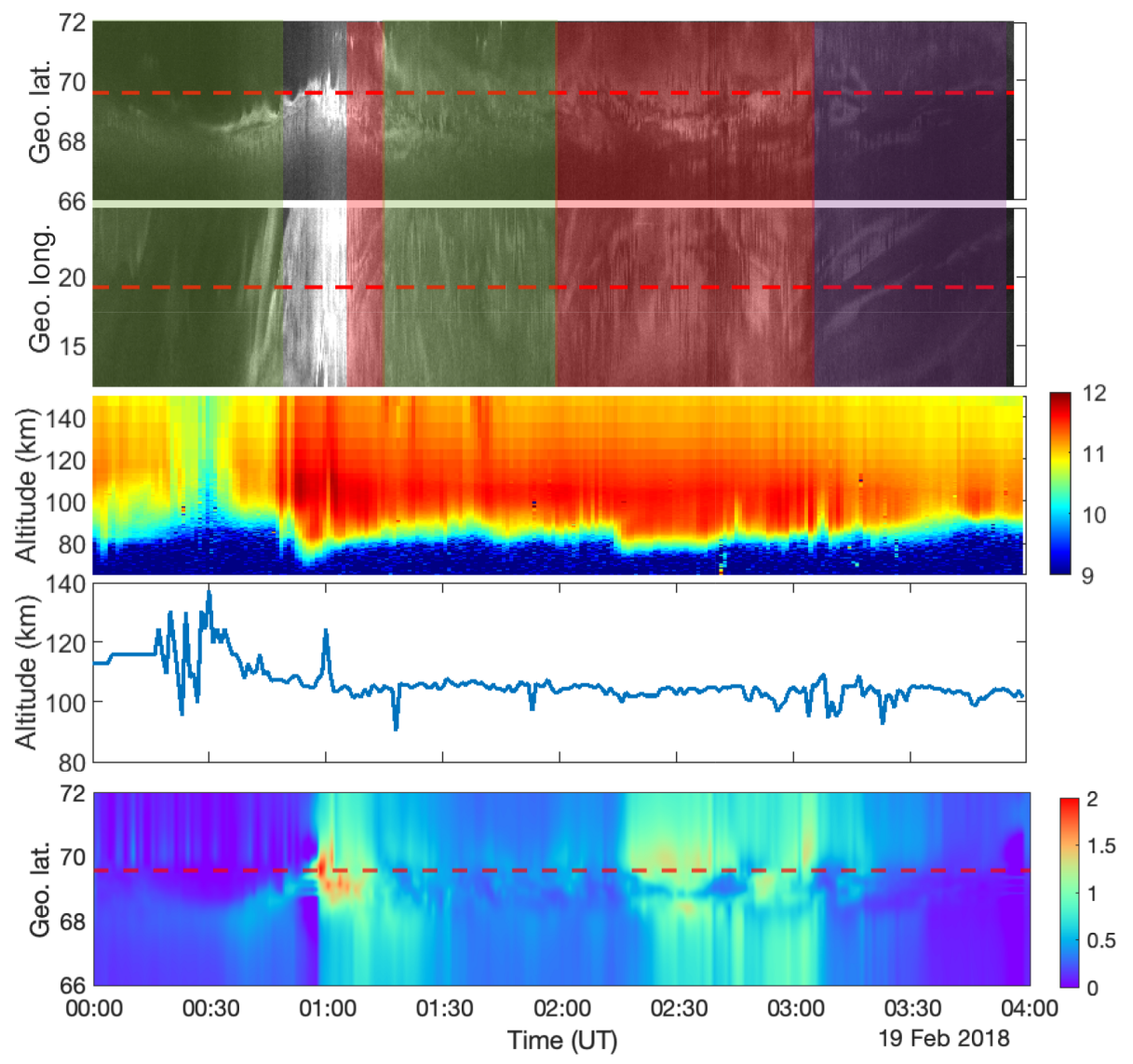

Figure 4. Similar to Figs. 2 and 3 but on 19 February 2018 with an additional panel of KAIRA CNA riogram (in dB). The dashed red line overlaid in the riogram is the EISCAT FOV.

however, during PPA a substantial number of data points have values above $0.5 \mathrm{~dB}$ and reach values greater than $1 \mathrm{~dB}$. Most of the high CNA values are observed during the late MLT period (after 3 MLT), which is consistent with the period of high ionization at lower altitudes observed by the EISCAT radars (see Fig. 6). On average, CNA index values during PPA are also higher, at $0.33 \mathrm{~dB}$, compared to PA $(0.23 \mathrm{~dB})$ and APA $(0.17 \mathrm{~dB})$ as shown by the color-coded lines in Fig. 7.

\section{Discussions}

The primary purpose of this study is to investigate the differences in fluxes and energies of electrons during different types of pulsating aurora using EISCAT radar electron measurements and KAIRA riometric observations as proxies. Based on keograms generated from high-resolution $(\sim 10 \mathrm{~s})$ KIL and ABK ASC images, we identified 39 APA, 35 PPA, and 18 PA types, with a total of 92 events, also observed by EISCAT radar. From the collective duration of time, APA was observed for a substantial period of time of $58 \mathrm{~h}$, followed by PPA for $43 \mathrm{~h}$ and PA for $21 \mathrm{~h}$. Grono and Donovan
(2020) reported the highest probability occurrence of APA and lowest occurrence of PPA using 10 years of ASC data from North America. In our study, PPA was more dominant than PA. The location and precipitation energy of the magnetospheric electrons responsible for the different types of PsA have been reported to be different (Yang et al., 2019; Grono and Donovan, 2020). The change in the patch sizes during PsAs is also suggested to be an indication of energy deposition in the atmosphere (Partamies et al., 2017, 2019). However, detailed studies about the precipitation energies and the mechanisms behind different structures of PsA are still required. The magnitude of the maximum electron density and its altitude provide both the flux and the energy information about the precipitating PsA electrons. From the electron density measurements, the differences in the magnitude of the electron density and the height of the maximum electron density among the three types of PsA were significant. The statistical findings presented in this study suggested that PPA has a higher energy range compared to PA and APA types, on average. This is contrary to the results from Yang et al. (2019), which reported that APA has a higher energy range compared to PPA. We used KAIRA CNA data to further show the differences in energy deposition during 

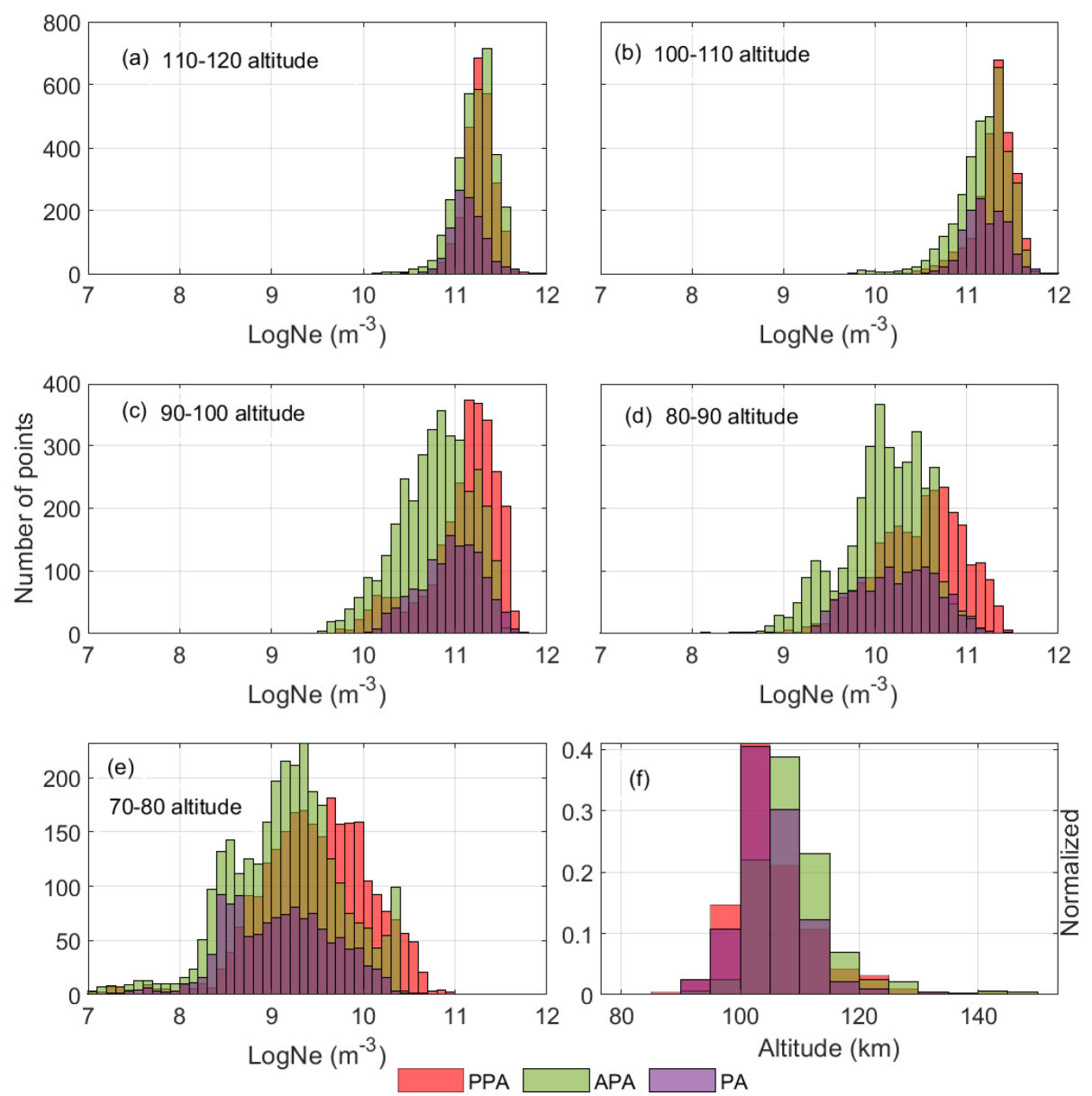

Figure 5. Histogram of EISCAT electron density measurements averaged between (a) 110 and $120 \mathrm{~km}$, (b) 100 and $110 \mathrm{~km}$, (c) 90 and $100 \mathrm{~km}$, (d) 80 and $90 \mathrm{~km}$, (e) 70 and $80 \mathrm{~km}$, and (f) altitude of maximum electron density during different types of pulsating aurora.

the different PsAs. Yang et al. (2019) analyzed CNA from a riometer in Canada to study 12 PsA events (7 APA and 6 PPA) and showed that CNA is systematically higher during APA than during PPA. They suggested that APA has a higher energy range than PPA by further providing evidence from a single event of FAST satellite measurements of electron energy. However, in this statistical study, which has a significant number of events for each PsA type, we found that PPA electron energies often have a higher energy range than APA, and PA energies lie in between the two. It has been established that both CNA (Wild et al., 2010; Rodger et al., 2012) and pulsating aurora (Jones et al., 2009; Partamies et al., 2017) extend over a range of altitudes. Thus, such a contradiction might depend on which altitude the pulsating aurora and CNA were observed at. It is also possible to find cases where energies of APA electrons are higher than those of PPA electrons, specifically in the energy range below the energy limit $(30 \mathrm{keV})$ measured by FAST. The stopping altitude of these electrons is above $95 \mathrm{~km}$ (Turunen et al., 2009). However, in this study, most of the energy (ionization) differences between the types were observed below $100 \mathrm{~km}$.
This suggests that in a higher energy range $(\sim>30 \mathrm{keV})$ PPA electrons' energy is typically higher than that of APA electrons. Riometers also respond to precipitating electrons below $30 \mathrm{keV}$; such particles deposit their energy above $90 \mathrm{~km}$, which is the D region in Fig. 6. To further explore the energy difference between PsA types, we use the KAIRA CNA. The CNA values from KAIRA suggest that the PPA electrons have higher energies to ionize at lower altitudes as compared to APA. The KAIRA CNA observations showed that the values could reach $1 \mathrm{~dB}$, specifically during PPA types. Such high absorption values are comparable to values during auroral substorms. However, the average CNA values during APA, PPA, and PA were $0.17,0.33$, and $0.23 \mathrm{~dB}$, respectively (Fig. 7).

In the late MLT sector (after 5MLT), PPA and PA are more common with higher electron density at a lower altitude (see Fig. 6). In this study, the occurrence of PA was entirely confined to after 2 MLT. The non-existence of PA before magnetic midnight is also reported by Grono and Donovan (2020). APA is dominant between 2 and 5 MLT, which is also consistent with their study. In terms of the order of 

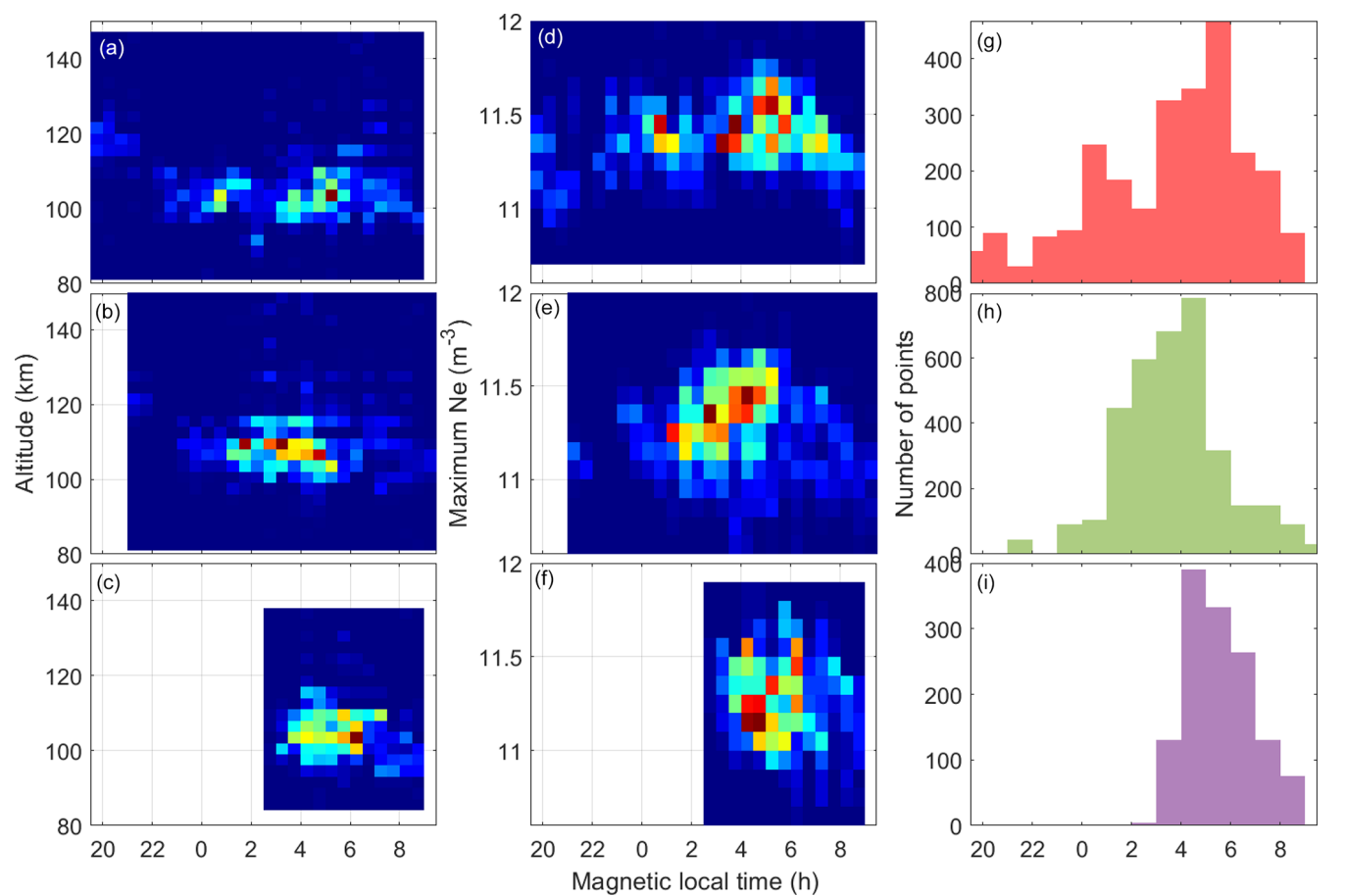

Figure 6. Two-dimensional histogram of altitude of maximum electron density (a-c), magnitude of maximum electron density (d-f), and distribution of the occurrence of data points $(\mathbf{g}-\mathbf{i})$ during different types of pulsating aurora: PPA, APA, and PA from top to bottom.

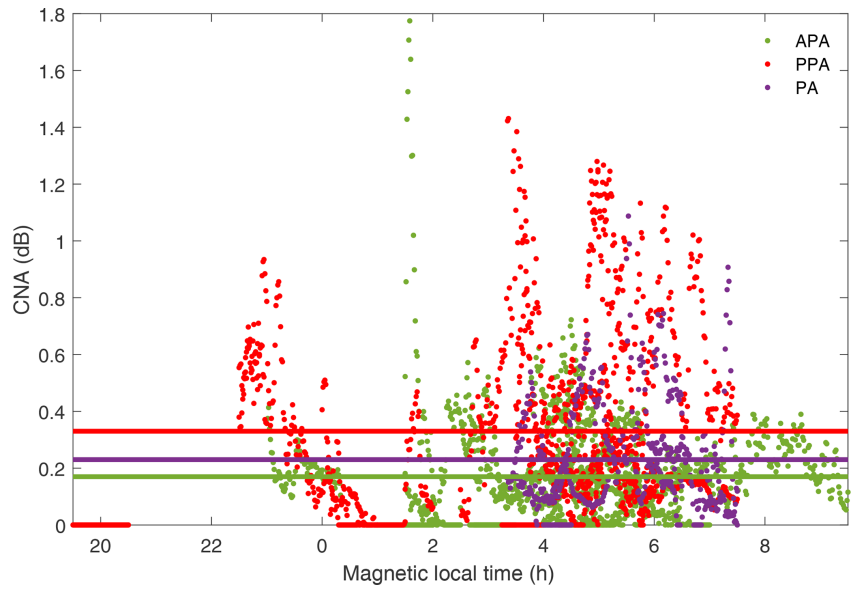

Figure 7. KAIRA cosmic noise absorption (CNA) during different types of pulsating aurora. Color-coded horizontal lines are the average CNA for respective PsA types.

occurrence, APA tends to be more dominant first, and then PPA or PA follows. Such an order of occurrence is also reported in Grono and Donovan (2020). As pointed out in their study, it is still unclear if APA is the onset of the two PsA types. However, this order of occurrence is also an indication that PPA and PA might be associated with higher energies as compared to APA. In the radiation belt, both the distribution of energetic electrons and chorus wave activity are dependent on MLT (Aryan et al., 2014; Allison et al., 2017).
Allison et al. (2017) showed the persistence of a high flux of electrons with energy $>30 \mathrm{keV}$ throughout the dawn sector. On the other hand, Aryan et al. (2014) showed that chorus wave activity is dominant in the morning-to-noon period. Thus, the higher electron density observed late in the morning in this study could be the result of the combination of the two, which include the source and mechanisms for energetic electron precipitation (see, e.g., Lam et al., 2010). Oyama et al. (2017) also suggested that the auroral patch formation in the post-midnight-to-dawn sector is associated with the development of energetic electron precipitation, despite the low level of geomagnetic activity. Hosokawa and Ogawa (2015) also reported the descent of the peak electron density associated with an increase in precipitation energy in the later MLT sector. Their statistical study of 21 PsA events showed that the peak height of PsA moves below $100 \mathrm{~km}$ after 6 MLT. The layer thickness of the categories is also observed to be different. PPA is the thickest structure, at $40 \mathrm{~km}$, while PA is the thinnest structure, at $20 \mathrm{~km}$. Thus, the thick ionization layer during PPA is also associated with precipitating electrons with a broader energy spectrum. This further indicates that the PPA is the most important PsA type in the D region.

In this study, we found a significant ionization of around $70 \mathrm{~km}$ during PPA and PA, which corresponds to $200 \mathrm{keV}$ energy. Such hard precipitation at this altitude is capable of changing the chemistry of the atmosphere by destroying mesospheric ozone (Turunen et al., 2016; Tesema et al., 2020). The type of PsA most likely to contribute largely to 
such destruction of ozone is PPA (Fig. 6). Most of the low fluxes in the higher-energy end of PsA spectra observed by Tesema et al. (2020) might account for APA types. This probable energy spectra difference from satellite measurements among the categories should be investigated in the future. If exclusively associated with APA, the low-flux scenario with no chemical changes in their study also suggests that it could be possible to visually differentiate which type causes chemical changes and which does not.

\section{Conclusions}

By combining ASC images and EISCAT radar experiments, we identified 39 APA, 35 PPA, and 18 PA types. We used the ionization level to investigate the electron flux and energy range difference between them. The CNA measured by the KAIRA riometer is also used to support the observations. The ionization level during PPA was considerably larger than APA in the region below $100 \mathrm{~km}$. However, the ionization level above $100 \mathrm{~km}$ has no significant difference between the two PsA types, while PA showed a low ionization level. Lower altitudes of the maximum electron density during PPA in the late MLT sector were observed. This suggests that the flux and energy of electrons during PPA are relatively higher than during APA. The CNA from KAIRA was also consistent with the EISCAT electron density results: higher CNA values during PPA $(\sim>0.5 \mathrm{~dB})$ after 3 MLT and lower CNA values during APA $(\sim<0.5 \mathrm{~dB})$ after 5 MLT. We also observed a high ionization level down to $70 \mathrm{~km}$ in EISCAT measurements, which corresponds to precipitation of relativistic electrons. The mechanisms responsible for the different types of PsA are still unclear, but on average this study showed that the precipitating electron spectra during the three types of PsA have significant differences, specifically in the higherenergy tail. To understand the sources of electrons during different types of pulsating auroras, an ideal combination of measurements would be satellite measurements in the magnetosphere, ground-based optical and radar measurements, and precipitation measurements from a low-latitude satellite. Such combinations will be sought in the future.

Data availability. The quick-look keograms for event selection are available at https://space.fmi.fi/MIRACLE/ASC/?page=keograms (Finnish Metrological Institute (FMI), 2020, last access: 28 June 2020). All-sky camera data are obtainable from the FMIMIRACLE network database, which can be requested from FMI (kirsti.kauristie@fmi.fi). High-resolution keograms generated from ASC images and the PsA category event list are available at https://doi.org/10.6084/m9.figshare.12559127 (Tesema, 2020). The 1 min resolution of EISCAT data used in this analysis is available at http://portal.eiscat.se/schedule/schedule.cgi (EISCAT Scientific Association, 2020, last access: 28 June 2020). The interferometric riometry images and keograms are based on cross-correlation statistics data, which are available on request from the KAIRA PI, So- dankylä Geophysical Observatory, http://www.sgo.fi/KAIRA (Sodankylä Geophysical Observatory, 2020).

Supplement. The supplement related to this article is available online at: https://doi.org/10.5194/angeo-38-1191-2020-supplement.

Author contributions. All authors contributed by providing necessary data, participating in discussions, and writing the paper.

Competing interests. The authors declare that they have no conflict of interest.

Special issue statement. This article is part of the "Special Issue on the joint 19th International EISCAT Symposium and 46th Annual European Meeting on Atmospheric Studies by Optical Methods". It is a result of the 19th International EISCAT Symposium 2019 and 46th Annual European Meeting on Atmospheric Studies by Optical Methods, Oulu, Finland, 19-23 August 2019.

Acknowledgements. The funding support for the work of Fasil Tesema and Hilde Nesse Tyssøy is provided by the Norwegian Research Council (NRC) under CoE contract 223252. In addition, the work of Noora Partamies is supported by NRC project 287427. The work of Derek McKay is partly supported by Academy of Finland project 322535. We thank Kirsti Kauristie, S. Mäkinen, J. Mattanen, A. Ketola, and C.-F. Enell for maintaining the MIRACLE camera network and data flow. KAIRA was funded by the University of Oulu and the FP7 European Regional Development Fund and is operated by Sodankylä Geophysical Observatory with support from the University of Troms $\emptyset$ and volunteer effort.

Financial support. This research has been supported by the Norwegian Research Council (grant nos. 223252 and 287427), and the Academy of Finland (grant no. 322535).

Review statement. This paper was edited by Daniel Whiter and reviewed by two anonymous referees.

\section{References}

Allison, H. J., Horne, R. B., Glauert, S. A., and Del Zanna, G.: The magnetic local time distribution of energetic electrons in the radiation belt region, J. Geophys. Res.-Space, 122, 8108-8123, https://doi.org/10.1002/2017JA024084, 2017.

Aryan, H., Yearby, K., Balikhin, M., Agapitov, O., Krasnoselskikh, V., and Boynton, R.: Statistical study of chorus wave distributions in the inner magnetosphere using $A e$ and solar wind parameters, J. Geophys. Res.-Space, 119, 6131-6144, https://doi.org/10.1002/2014JA019939, 2014. 
Bland, E. C., Partamies, N., Heino, E., Yukimatu, A. S., and Miyaoka, H.: Energetic Electron Precipitation Occurrence Rates Determined Using the Syowa East SuperDARN Radar, J. Geophys. Res.-Space, 124, 6253-6265, https://doi.org/10.1029/2018ja026437, 2019.

Böinger, T., Kaila, K., Rasinkangas, R., Pollari, P., Kangas, J., Trakhtengerts, V., Demekhov, A., and Turunen, T.: An EISCAT study of a pulsating auroral arc: simultaneous ionospheric electron density, auroral luminosity and magnetic field pulsations, J. Atmos. Terr. Phys., 58, 23-35, https://doi.org/10.1016/00219169(95)00017-8, 1996

EISCAT Scientific Association: VHF and UHF radar analysed data, available at: http://portal.eiscat.se/schedule/schedule.cgi, last access: 4 November 2020.

Finnish Metrological Institute (FMI): Magnetometers-Ionospheric Radars-All-Sky Cameras Large Experiment (MIRACLE) project, FMI All-sky camera quicklook data, available at: https://space.fmi.fi/MIRACLE/ASC/?page=keograms, last access: 4 Novemeber 2020.

Grandin, M., Kero, A., Partamies, N., McKay, D., Whiter, D., Kozlovsky, A., and Miyoshi, Y.: Observation of pulsating aurora signatures in cosmic noise absorption data, Geophys. Res. Lett., 44, 5292-5300, https://doi.org/10.1002/2017GL073901, 2017.

Grono, E. and Donovan, E.: Differentiating diffuse auroras based on phenomenology, Ann. Geophys., 36, 891-898, https://doi.org/10.5194/angeo-36-891-2018, 2018.

Grono, E. and Donovan, E.: Surveying pulsating auroras, Ann. Geophys., 38, 1-8, https://doi.org/10.5194/angeo-38-1-2020, 2020.

Hosokawa, K. and Ogawa, Y.: Pedersen current carried by electrons in auroral D-region, Geophys. Res. Lett., 37, L18103, https://doi.org/10.1029/2010GL044746, 2010.

Hosokawa, K. and Ogawa, Y.: Ionospheric variation during pulsating aurora, J. Geophys. Res.-Space, 120, 5943-5957, https://doi.org/10.1002/2015JA021401, 2015.

Hosokawa, K., Ogawa, Y., Kadokura, A., Miyaoka, H., and Sato, N.: Modulation of ionospheric conductance and electric field associated with pulsating aurora, J. Geophys. Res.-Space, 115, A03201, https://doi.org/10.1029/2009JA014683, 2010.

Jones, S. L., Lessard, M. R., Fernandes, P. A., Lummerzheim, D., Semeter, J. L., Heinselman, C. J., Lynch, K. A., Michell, R. G., Kintner, P. M., Stenbaek-Nielsen, H. C., and Asamura, K.: PFISR and ROPA observations of pulsating aurora, J. Atmos. Sol.-Terr. Phy., 71, 708-716, https://doi.org/10.1016/j.jastp.2008.10.004, 2009.

Jones, S. L., Lessard, M. R., Rychert, K., Spanswick, E., and Donovan, E.: Large-scale aspects and temporal evolution of pulsating aurora, J. Geophys. Res.-Space, 116, 1-7, https://doi.org/10.1029/2010JA015840, 2011.

Jones, S. L., Lessard, M. R., Rychert, K., Spanswick, E., Donovan, E., and Jaynes, A. N.: Persistent, widespread pulsating aurora: A case study, J. Geophys. Res.-Space, 118, 2998-3006, https://doi.org/10.1002/jgra.50301, 2013.

Lam, M. M., Horne, R. B., Meredith, N. P., Glauert, S. A., MoffatGriffin, T., and Green, J. C.: Origin of energetic electron precipitation $>30 \mathrm{keV}$ into the atmosphere, J. Geophys. Res., 115, A00F08, https://doi.org/10.1029/2009JA014619, 2010.

Lessard, M. R.: A Review of Pulsating Aurora, Auror. Phenomenol. Magnetos. Process. Earth Other Planets, 55-68, https://doi.org/10.1029/GM197, 2012.
McEwen, D. J., Yee, E., Whalen, B. A., and Yau, A. W.: Electron energy measurements in pulsating auroras, Can. J. Phys., 59, 11061115, https://doi.org/10.1139/p81-146, 1981.

McKay-Bukowski, D., Vierinen, J., Virtanen, I. I., Fallows, R., Postila, M., Ulich, T., Wucknitz, O., Brentjens, M., Ebbendorf, N., Enell, C., Gerbers, M., Grit, T., Gruppen, P., Kero, A., Iinatti, T., Lehtinen, M., Meulman, H., Norden, M., Orispää, M., Raita, T., de Reijer, J. P., Roininen, L., Schoenmakers, A., Stuurwold, K., and Turunen, E.: KAIRA: The Kilpisjärvi Atmospheric Imaging Receiver Array - System Overview and First Results, IEEE T. Geosci. Remote Sens., 53, 1440-1451, https://doi.org/10.1109/TGRS.2014.2342252, 2015.

McKay, D., Partamies, N., and Vierinen, J.: Pulsating aurora and cosmic noise absorption associated with growth-phase arcs, Ann. Geophys., 36, 59-69, https://doi.org/10.5194/angeo-36-59-2018, 2018.

Milan, S. E., Hosokawa, K., Lester, M., Sato, N., Yamagishi, H., and Honary, F.: D region HF radar echoes associated with energetic particle precipitation and pulsating aurora, Ann. Geophys., 26, 1897-1904, https://doi.org/10.5194/angeo-26-1897-2008, 2008.

Miyoshi, Y., Katoh, Y., Nishiyama, T., Sakanoi, T., Asamura, K., and Hirahara, M.: Time of flight analysis of pulsating aurora electrons, considering wave-particle interactions with propagating whistler mode waves, J. Geophys. Res.-Space, 115, 1-7, https://doi.org/10.1029/2009JA015127, 2010.

Miyoshi, Y., Oyama, S., Saito, S., Kurita, S., Fujiwara, H., Kataoka, R., Ebihara, Y., Kletzing, C., Reeves, G., Santolik, O., Clilverd, M., Rodger, C. J., Turunen, E., and Tsuchiya, F.: Energetic electron precipitation associated with pulsating aurora: EISCAT and Van Allen Probe observations, J. Geophys. Res.-Space, 120 2754-2766, https://doi.org/10.1002/2014JA020690, 2015.

Nishimura, Y., Bortnik, J., Li, W., Thorne, R. M., Lyons, L. R., Angelopoulos, V., Mende, S. B., Bonnell, J. W., Le Contel, O., Cully, C., Ergun, R., and Auster, U.: Identifying the driver of pulsating aurora, Science, 330, 81-84, https://doi.org/10.1126/science.1193186, 2010.

Nishimura, Y., Bortnik, J., Li, W., Thorne, R. M., Chen, L., Lyons, L. R., Angelopoulos, V., Mende, S. B., Bonnell, J., Le Contel, O., Cully, C., Ergun, R., and Auster, U.: Multievent study of the correlation between pulsating aurora and whistler mode chorus emissions, J. Geophys. Res.-Space, 116, 1-11, https://doi.org/10.1029/2011JA016876, 2011.

Nishimura, Y., Lessard, M. R., Katoh, Y., Miyoshi, Y., Grono, E., Partamies, N., Sivadas, N., Hosokawa, K., Fukizawa, M., Samara, M., Michell, R. G., Kataoka, R., Sakanoi, T., Whiter, D. K., Oyama, S. ichiro, Ogawa, Y., and Kurita, S.: Diffuse and Pulsating Aurora, Space Sci. Rev., 216, 4, https://doi.org/10.1007/s11214-019-0629-3, 2020.

Oyama, S.-I., Shiokawa, K., Miyoshi, Y., Hosokawa, K., Watkins, B. J., Kurihara, J., Tsuda, T. T., and Fallen, C. T.: Lower thermospheric wind variations in auroral patches during the substorm recovery phase, J. Geophys. Res.-Space, 121, 3564-3577, https://doi.org/10.1002/2015JA022129, 2016.

Oyama, S., Kero, A., Rodger, C. J., Clilverd, M. A., Miyoshi, Y., Partamies, N., Turunen, E., Raita, T., Verronen, P. T., and Saito, S.: Energetic electron precipitation and auroral morphology at the substorm recovery phase, J. Geophys. Res.-Space, 122, 6508-6527, https://doi.org/10.1002/2016JA023484, 2017. 
Partamies, N., Whiter, D., Kadokura, A., Kauristie, K., Nesse Tyssøy, H., Massetti, S., Stauning, P., and Raita, T.: Occurrence and average behavior of pulsating aurora, J. Geophys. Res.Space, 122, 5606-5618, https://doi.org/10.1002/2017JA024039, 2017.

Partamies, N., Bolmgren, K., Heino, E., Ivchenko, N., Borovsky, J. E., and Sundberg, H.: Patch size evolution during pulsating aurora, J. Geophys. Res.-Space, 124, 4725-4738, https://doi.org/10.1029/2018JA026423, 2019.

Rees, M. H.: Auroral electrons, Space Sci. Rev., 10, 413-441, https://doi.org/10.1007/BF00203621, 1969.

Rishbeth, H. and Williams, P. J. S.: The EISCAT ionospheric radar: The system and its early results, Q. J. Roy. Astron. Soc., 26, 478512, 1985.

Rodger, C. J., Clilverd, M. A., Kavanagh, A. J., Watt, C. E. J., Verronen, P. T., and Raita, T.: Contrasting the responses of three different ground-based instruments to energetic electron precipitation, Radio Sci., 47, RS2021, https://doi.org/10.1029/2011RS004971, 2012.

Royrvik, O. and Davis, T. N.: Pulsating aurora local and global morphology, J. Geophys. Res., 82, 4720-4740, 1977.

Sangalli, L., Partamies, N., Syrjäsuo, M., Enell, C. F., Kauristie, K., and Mäkinen, S.: Performance study of the new EMCCDbased all-sky cameras for auroral imaging, Int. J. Remote Sens., 32, 2987-3003, https://doi.org/10.1080/01431161.2010.541505, 2011.

Sato, N., Wright, D. M., Carlson, C. W., Ebihara, Y., Sato, M., Saemundsson, T., Milan, S. E., and Lester, M.: Generation region of pulsating aurora obtained simultaneously by the FAST satellite and a Syowa-Iceland conjugate pair of observatories, J. Geophys. Res.-Space, 109, 1-15, https://doi.org/10.1029/2004JA010419, 2004.

Sodankylä Geophysical Observatory: Kilpisjärvi Atmospheric Imaging Receiver Array (KAIRA) project, available at: https: //www.sgo.fi/KAIRA/, last access: 4 Novemeber 2020.

Tesema, F.: Replication data for: Observations of precipitation energies during different types of pulsating aurora, Dataset, figshare, https://doi.org/10.6084/m9.figshare.12559127, 2020.
Tesema, F., Partamies, N., Tyssøy, H. N., Kero, A., and SmithJohnsen, C.: Observations of electron precipitation during pulsating aurora and its chemical impact, J. Geophys. Res.-Space, 125, e2019JA027713, https://doi.org/10.1029/2019JA027713, 2020.

Turunen, E., Verronen, P. T., Seppälä, A., Rodger, C. J., Clilverd, M. A., Tamminen, J., Enell, C. F., and Ulich, T.: Impact of different energies of precipitating particles on $\mathrm{NO}_{x}$ generation in the middle and upper atmosphere during geomagnetic storms, J. Atmos. Sol.-Terr. Phys., 71, 1176-1189, https://doi.org/10.1016/j.jastp.2008.07.005, 2009.

Turunen, E., Kero, A., Verronen, P. T., Miyoshi, Y., Oyama, S. I., and Saito, S.: Mesospheric ozone destruction by high-energy electron precipitation associated with pulsating aurora, J. Geophys. Res., 121, 11852-11861, https://doi.org/10.1002/2016JD025015, 2016.

Wahlund, J. E., Opgenoorth, H. J., and Rothwell, P.: Observations of thin auroral ionization layers by EISCAT in connection with pulsating aurora, J. Geophys. Res.-Space, 94, 17223-17233, https://doi.org/10.1029/JA094iA12p17223, 1989.

Watanabe, M., Kadokura, A., Sato, N., and Saemundsson, T.: Absence of geomagnetic conjugacy in pulsating auroras, Geophys. Res. Lett., 34, L15107, https://doi.org/10.1029/2007GL030469, 2007.

Wild, P., Honary, F., Kavanagh, A. J., and Senior, A.: Triangulating the height of cosmic noise absorption: A method for estimating the characteristic energy of precipitating electrons, J. Geophys. Res., 115, A12326, https://doi.org/10.1029/2010JA015766, 2010.

Yamamoto, T.: On the temporal fluctuations of pulsating auroral luminosity, J. Geophys. Res., 93, 897, https://doi.org/10.1029/JA093iA02p00897, 1988.

Yang, B., Spanswick, E., Liang, J., Grono, E., and Donovan, E.: Responses of Different Types of Pulsating Aurora in Cosmic Noise Absorption, Geophys. Res. Lett., 46, 5717-5724, https://doi.org/10.1029/2019GL083289, 2019. 